\title{
Differences in larval survival and IgG response patterns in long-lasting infections by Trichinella spiralis, Trichinella britovi and Trichinella pseudospiralis in pigs
}

Edoardo Pozio ${ }^{1}$, Giuseppe Merialdi' ${ }^{2}$ Elio Licata ${ }^{3}$, Giacinto Della Casa ${ }^{4}$, Massimo Fabiani ${ }^{1}$, Marco Amati ${ }^{1}$, Simona Cherchi ${ }^{1}$, Mattia Ramini ${ }^{2}$, Valerio Faeti ${ }^{4}$, Maria Interisano ${ }^{1}$, Alessandra Ludovisi ${ }^{1}$, Gianluca Rugna ${ }^{2}$, Gianluca Marucci' ${ }^{1}$ Daniele Tonanzi ${ }^{1}$ and Maria Angeles Gómez-Morales ${ }^{1 *}$

\begin{abstract}
Background: Domesticated and wild swine play an important role as reservoir hosts of Trichinella spp. and a source of infection for humans. Little is known about the survival of Trichinella larvae in muscles and the duration of antiTrichinella antibodies in pigs with long-lasting infections.

Methods: Sixty pigs were divided into three groups of 20 animals and infected with 10,000 larvae of Trichinella spiralis, Trichinella britovi or Trichinella pseudospiralis. Four pigs from each group were sacrificed at 2, 6, 12, 18 and 24 months post-infection (p.i.) and the number of larvae per gram (LPG) of muscles was calculated. Serum samples were tested by ELISA and western blot using excretory/secretory (ES) and crude antigens.
\end{abstract}

Results: Trichinella spiralis showed the highest infectivity and immunogenicity in pigs and larvae survived in pig muscles for up to 2 years p.i. In these pigs, the IgG level significantly increased at 30 days p.i. and reached a peak at about 60 days p.i., remaining stable until the end of the experiment. In T. britovi-infected pigs, LPG was about 70 times lower than for T. spiralis at 2 months p.i. and only very few infecting larvae were detected at 6 months p.i., whereas no larvae were detected at 12, 18 and 24 months p.i. At 6 months p.i., degenerated/calcified larvae and cysts were detected in the muscles by trichinoscopy and histology. The lgG pattern showed by T. britovi-infected pigs was similar to that of T. spiralis-infected pigs, although seroconversion occurred some days later. The larval burden of T. pseudospiralis was slightly greater than for T. britovi at 2 months p.i., but no larvae were detected at 6 and 12 months p.i. In T. pseudospiralis-infected pigs, seroconversion occurred slowly, as in T. britovi-infected pigs. The lgG level showed a significant drop at 6 months p.i. and declining to the cut-off value at 12 months p.i.

Conclusions: The longer survival of T. spiralis in pigs in comparison with the other two species highlights its exceptional dissemination potential. These results provide an explanation of the controversial data collected by parasitological and serological tools in the course of epidemiological investigations.

Keywords: Trichinella spiralis, Trichinella britovi, Trichinella pseudospiralis, Pig, Larval burden, Immune response, ELISA, Western blot, Epidemiology

\footnotetext{
*Correspondence: mariaangeles.gomezmorales@iss.it

1 Department of Infectious Diseases, Istituto Superiore di Sanità, viale Regina Elena 299, 00161 Rome, Italy

Full list of author information is available at the end of the article
}

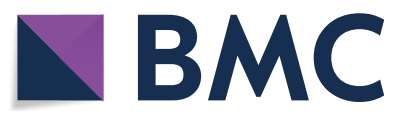

(c) The Author(s) 2020. This article is licensed under a Creative Commons Attribution 4.0 International License, which permits use, sharing, adaptation, distribution and reproduction in any medium or format, as long as you give appropriate credit to the original author(s) and the source, provide a link to the Creative Commons licence, and indicate if changes were made. The images or other third party material in this article are included in the article's Creative Commons licence, unless indicated otherwise in a credit line to the material. If material is not included in the article's Creative Commons licence and your intended use is not permitted by statutory regulation or exceeds the permitted use, you will need to obtain permission directly from the copyright holder. To view a copy of this licence, visit http://creativeco mmons.org/licenses/by/4.0/. The Creative Commons Public Domain Dedication waiver (http://creativecommons.org/publicdomain/ zero/1.0/) applies to the data made available in this article, unless otherwise stated in a credit line to the data. 


\section{Background}

The history of the biology and epidemiology of parasites of the genus Trichinella has been strongly linked to swine since the first discovery of this nematode in a naturally infected animal [1]. After this first report and in the following 154 years, pork and pork-derived products from domestic and wild swine have represented and still represent the main source of trichinellosis infections for humans $[2,3]$. From the mid-19th century up to recent years, there have been numerous investigations on the biology and epidemiology of these zoonotic nematodes in swine. Of the 13 known taxa of the genus Trichinella, as many as seven (Trichinella spiralis, T. nativa, T. britovi, T. pseudospiralis, T. nelsoni, T. papuae and T. zimbabwensis) have been detected in naturally or experimentally infected swine, with varying levels of both infectivity and persistence [4-10]. For this reason, the domestic pig has been the subject of numerous studies since the 19th century $[11,12]$.

According to the international literature, $T$. spiralis is the species most frequently detected in domestic and wild swine (Sus scrofa), followed by T. britovi and $T$. pseudospiralis [13-18]. Extensive experimental investigations have demonstrated a different larval burden and immune response for Trichinella species in swine at 60 [8] and 70 [7] days post-infection and up to 40 weeks [6]. No systematic information is available on the survival of Trichinella larvae and the presence of detectable antiTrichinella IgG in pigs experimentally infected by different Trichinella species for longer time periods.

Epidemiological investigations carried out in several world regions to determine Trichinella prevalence by artificial digestion of muscle tissues and/or by serology in domestic and wild swine have revealed a discrepancy between parasitological and serological positivity [1930]. This inconsistency has created uncertainty as to the specificity and/or sensitivity of the tests and the consequent epidemiological value of the results.

The aim of this study was to evaluate the infectivity and larval persistence in muscle of T. spiralis, T. britovi and $T$. pseudospiralis in experimentally infected pigs tested for a two-year period. The persistence of detectable antibodies and their relationship with larva recovery were also studied, as these factors provide important epidemiological information.

\section{Methods}

\section{Study design, pigs and Trichinella spp. strains}

A batch of 60 homogenous (Duroc $\times$ Large White) pigs, 15 weeks of age, $35 \mathrm{~kg}$, was divided into 3 groups of 20 pigs each and infected with 10,000 larvae as follows: group 1, T. spiralis (ISS3, domestic pig, Poland); group 2, T. britovi (ISS2, red fox, Vulpes vulpes, Italy); and group
3, T. pseudospiralis (ISS13, raccoon, Procyon lotor, Russia). Previously, these Trichinella strains had been maintained by serial passages in CD1 Swiss mice for more than 20 years, never in pigs before this study. Each group of 20 pigs was housed in a separate fenced enclosure.

Ten ml of blood was collected from the jugular vein of each pig 10 days before infection, on the day of infection (time 0 ), and once a month until slaughter. The sera were isolated from clotted blood by centrifugation and then frozen at $-20{ }^{\circ} \mathrm{C}$. Based on previous investigations $[6,8]$, blood samples were also collected during the expected seroconversion period from pigs in the three groups at 24 days post-infection (p.i.) (six T. spiralis-, five T. britovi- and five T. pseudospiralis-infected pigs), 35 days p.i. (all 60 pigs) and 42 days p.i. (five pigs: two infected with $T$. britovi and three with $T$. pseudospiralis, that had been seronegative at 35 days p.i.). Four pigs in each group/Trichinella species were killed at 2, 6, 12, 18 and 24 months p.i. Each pig was weighed before slaughter, and mean \pm standard deviation (SD) weights were: 59 $\pm 5.5 \mathrm{~kg}$ at 2 months p.i., $139.2 \pm 15.3 \mathrm{~kg}$ at 6 months p.i., $144 \pm 20.9 \mathrm{~kg}$ at 12 months p.i., $198.5 \pm 27.6 \mathrm{~kg}$ at 18 months p.i., and $241.9 \pm 18 \mathrm{~kg}$ at 24 months p.i. Then pigs were sedated with $1 \mathrm{ml} / 20 \mathrm{~kg}$ of Azaperone, stunned with a captive-bolt, immediately jugulated and bled. The blood was collected in trays measuring about $80 \times 50$ $\mathrm{cm}$ so that it could clot and enable the collection of good quality serum. Each carcass was eviscerated, and the diaphragm and tongue were removed and weighed separately. The carcass was then cut lengthwise. The following cuts or muscles were dissected and weighed: diaphragm; tongue; masseter; neck; front (shoulder muscles) and hind (ham muscles) legs; loin; and ribs. For large muscles, part of the muscle nearest to the tendons was collected. About $150 \mathrm{~g}$ of each muscle or group of muscles was cut into fragments measuring about $2 \times 2 \mathrm{~cm}$ and preserved in plastic containers with labels stating the pig code number, muscle name, and slaughter date. Muscle samples were preserved at $4{ }^{\circ} \mathrm{C}$ for $24-48 \mathrm{~h}$ and then frozen at $20^{\circ} \mathrm{C}$ until digestion.

The pigs were housed in the Animal Care Unit of the Centro di Ricerca Zootecnica e Acquacoltura of San Cesario sul Panaro (Modena, Italy) according to European Directive 63/2010/EU.

\section{Detection of Trichinella spp. larvae in pig muscles}

One day before artificial digestion, the muscle samples were thawed at $4{ }^{\circ} \mathrm{C}$. One-hundred grams of each muscle, without fat and fascia, was digested using the reference method applied by the European Commission [31]. For T. pseudospiralis infected muscles, the digest of muscle samples of T. pseudospiralis infected pigs were immediately cooled on ice and allowed to settle for $20 \mathrm{~min}$ to 
stop the digestion process. Larvae were counted in triplicate under a stereomicroscope at $40 \times$ magnification.

\section{Detection of Trichinella spp. larvae in pig muscles by trichinoscopy and histology, reproductive capacity index in mice, and larva identification}

Within 24-48 h after slaughter, $100 \mathrm{~g}$ of the diaphragm of one pig from each of the three pig groups was digested as previously described and the larvae were washed, counted and injected per os into 2 mice (500 larvae each), to assess the reproductive capacity index (RCI, number of larvae collected/number of larvae injected). Ten larvae from each pig were stored in 90\% ethanol for Trichinella species identification by multiplex PCR [32]. Furthermore, 100 small pieces of oat-grain-sized diaphragm samples, collected from T. britovi- and T. pseudospiralisinfected pigs at 6 months p.i., were compressed between two thick glass plates until they became translucent and were examined individually to detect Trichinella larvae using a stereomicroscope at $15-40 \times$ magnification. The muscle tissue fragments containing a collagen cyst with or without larva were collected from the compressorium and fixed in $10 \%$ formalin. Tissue samples were embedded in paraffin and the histological section obtained from the paraffin blocks were Giemsa stained and examined under a light microscope.

\section{Serology}

The anti-Trichinella IgG from each individual serum were tested by excretory/secretory antigen (ES) ELISA, ES western blot (Wb), crude worm extract (CWE) ELISA and $\mathrm{CWE}-\mathrm{Wb}$ according to previous published protocols [33-35]. Briefly, the pig sera were diluted 1:50 and 1:100 for ELISA and Wb, respectively. Peroxidase-labelled antiswine IgG was diluted 1:30,000 (Kierkegaard and Perry Laboratories, Gaithersburg, MD, USA). The optical density (OD) was obtained by reading the reaction at 450 nm using an ELISA plate microtiter reader (Dynex Technologies, Chantilly, VA, USA). For each serum sample, an ELISA index $\left(\mathrm{E}_{\mathrm{I}}\right)$ expressed as a percentage of positivity was calculated according to Gómez-Morales et al. [34]. Positive control serum samples were from Trichinella infected pigs, whether naturally or experimentally infected, in which Trichinella larvae had been detected by artificial digestion and their sera had been tested positive by ELISA (OD range 1.000-2.870). The cut-off value, calculated as the mean $\pm 3 \mathrm{SD}$ of the $\mathrm{OD}$ values of the 880 serum samples from Trichinella-free pigs, was $18 \%$ (Additional file 1: Figure S1) [34].

The Wb analysis was carried out according to GómezMorales et al. [33, 35]. Briefly, $150 \mu \mathrm{g}$ of total proteins corresponding to T. spiralis ES antigens or CWE was diluted and loaded into $10 \%$ pre-cast NuPage Novex
Bis-Tris Gels ${ }^{\circledR}$ (Life Technologies, Carlsbad, CA, USA) as described in the instructions for electrophoresis using the XCell SureLock ${ }^{\circledR}$ Mini-Cell (Life Technologies). Proteins were separated using electrophoresis under reducing conditions and transferred to nitrocellulose (Bio-Rad, Hercules, CA, USA) at room temperature (RT) for $1 \mathrm{~h}$. The nitrocellulose filters were blocked with $5 \%$ skimmed milk in $1 \times$ Tris Borate Saline Tween (TBST, $50 \mathrm{mM}$ Tris $\mathrm{pH} 8.0,150 \mathrm{mM} \mathrm{NaCl}, 1 \%$ Tween 20 ) at $4{ }^{\circ} \mathrm{C}$ overnight and washed 3 times with $1 \times$ TBST. The nitrocellulose filters were cut into strips, each of which was then incubated with swine sera with $3 \% \mathrm{w} / \mathrm{v}$ skimmed milk (Sigma-Aldrich, Saint Louis, USA) in $1 \times$ TBST at RT for $1 \mathrm{~h}$. After washing 3 times with $1 \times$ TBST, the strips were incubated for $1 \mathrm{~h}$ with a 1:3000 dilution of goat anti-pig IgG conjugated with horseradish peroxidase (Bio-Rad).

\section{Statistical analysis}

The analysis considered larva concentrations as the number of larvae per gram (LPG) of muscle or group of muscles. For each Trichinella species, the number of LPG within each muscle or group of muscles was described using the mean with SD. Changes in mean LPG between two consecutive time-points were evaluated using the t-test. Differences in mean LPG among muscles or groups of muscles at different time-points were also evaluated by repeated measures analysis of variance (ANOVA), using the Bonferroni correction for pairwise comparisons. The rate of decrease in mean LPG between two consecutive time-points $\left(\mathrm{T}_{0}\right.$ and $\left.\mathrm{T}_{1}\right)$ due to an increase in muscle weight and a reduction in the number of larvae was estimated. The expected mean LPG at $\mathrm{T}_{1}$ in the absence of a reduction in LPG as $\mathrm{E}_{1}=\mathrm{N}_{0} / \mathrm{W}_{1}$ (where $\mathrm{N}_{0}$ is the LPG at $T_{0}$ and $W_{1}$ is the muscle weight at $T_{1}$ ) was calculated. The rate of decrease in mean LPG due to a reduction in the number of larvae was then calculated as $E_{1} /\left(\mu_{0}-\right.$ $\mu_{1}$ ), where $\mu_{0}$ and $\mu_{1}$ indicate the mean LPG at $T_{0}$ and the mean LPG at $T_{1}$, respectively. The rate of decrease in mean LPG due to an increase in muscle weight was calculated as $1-\mathrm{E}_{1} /\left(\mu_{0}-\mu_{1}\right)$.

For each Trichinella species, the trend of $\mathrm{E}_{\mathrm{I}}$ over time was evaluated using mixed regression models to account for dependency of observations among the individual pigs. $E_{I}$ was also compared among species at different time-points using ANOVA models with Bonferroni correction for pairwise comparisons. Finally, the relationship between LPG and the level of anti-Trichinella IgG by species, muscle or muscle group and time-point was evaluated using Pearson's correlation coefficient.

Statistical significance was set at $P<0.05$. Non-parametric tests were used to evaluate differences in mean LPG and $\mathrm{E}_{\mathrm{I}}$ between two or more groups of pigs (i.e. Wilcoxon rank-sum test and Kruskal-Wallis test). Results 
from parametric and non-parametric analyses led to the same conclusions, except in a very few cases analysed by the Wilcoxon rank-sum test. The analyses were performed using Stata/SE version 16.0 (StataCorp LLC, Texas, USA).

\section{Results}

One pig in the T. spiralis group died 2 weeks after infection and the animal was deleted from the trial. All the other T. spiralis- and T. britovi-infected pigs were killed at the established times according to the experimental design because larvae were present in the muscles and/ or because of persistent positive anti-Trichinella IgG responses. T. pseudospiralis-infected pigs were killed at 2 and 6 months p.i. according to the experimental design. All the other pigs $(n=12)$ were killed at 12 months p.i. due to the disappearance of larvae in the muscles of pigs killed 6 months before and the pronounced reduction in the IgG level below the cut-off in 8 out of 12 pigs. In the other 4 pigs, the $\mathrm{E}_{\mathrm{I}}$ values were still above the cut-off $(29.6 \% ; 41.9 \% ; 25.3 \% ; 24.6 \%)$ at 12 months p.i.

\section{Larval burden}

At two months p.i., T. spiralis showed the highest larval burden per $g$ of muscle in all muscles compared to the other two species (Fig. 1a; Additional file 2: Table S1). The highest larval burden was detected in the diaphragm (348 LPG, 95\% CI: 324-373) followed by the tongue (326 LPG, 95\% CI: 303-349), masseter (216 LPG, 95\% CI: 194-238) and shoulder (220 LPG, 95\% CI: 195-245), ribs (120 LPG, 95\% CI: 102-138), ham (77.7 LPG, 95\% CI: 62.2-93.2), neck (89.3 LPG, 95\% CI: 82.2-96.5) and loin (56.0 LPG, 95\% CI: 47.8-64.2). The variability of larval burden among the eight investigated muscle sites at 2, 6, 12, 18 and 24 months p.i. is shown in Fig. 1a and the statistically significant pairwise comparison in Additional file 2: Table S1.

Trichinella britovi showed the lowest larval burden in the eight investigated muscle sites compared to T. spiralis and T. pseudospiralis two months p.i. At this time p.i., the LPG in the diaphragm and tongue was 82 and 72 times lower than that of T. spiralis, respectively. At two months p.i., the highest larval burden was detected in the tongue (4.50 LPG, 95\% CI: 2.40-6.60) followed by the diaphragm (4.25 LPG, 95\% CI: 0.92-7.6), masseter (3.00 LPG, 95\% CI: 1.16-4.84), shoulder (1.65 LPG, 95\% CI: 0.30-2.99), ham (1.63 LPG, 95\% CI: 0.00-3.31), neck (1.43 LPG, 95\% CI: 0.19-2.66), ribs (0.79 LPG, 95\% CI: 0.24-1.34) and loin (0.58 LPG, 95\% CI: 0.22-0.94). At six months p.i., no larvae were detected in the tongue and masseter of the 4 pigs tested, and very few larvae were detected in the other six muscle sites of one pig and in the diaphragm of another. No larvae of T. britovi were detected by artificial digestion in any of the 8 investigated muscle sites at 12 , 18 and 24 months p.i. (Fig. 1b; Additional file 2: Table S1).

The larval burden for T. pseudospiralis was slightly higher than for T. britovi at two months p.i. At this timepoint, the LPG in the diaphragm and tongue was 45 and 37 times lower than for T. spiralis, respectively. At two months p.i., the highest larval burden was detected in the tongue (8.75 LPG, 95\% CI: 4.36-13.2), followed by the diaphragm (7.75 LPG, 95\% CI: 4.12-11.4), masseter (4.75 LPG, 95\% CI: 3.03-6.47), shoulder (4.50 LPG, 95\% CI: 3.20-5.80), neck (4.00 LPG, 95\% CI: 2.57-5.43), ribs (2.25 LPG, 95\% CI: 0.98-3.52), ham (2.0 LPG, 95\% CI: 1.18-2.82) and loin (1.50 LPG, 95\% CI: 0.92-2.08). At six months p.i., no larvae were detected in any of the eight investigated muscle sites in 4 pigs. At 12 months p.i., no larvae were detected in any of the other 12 pigs.

At six months p.i., the larval burden for $T$. spiralis showed a significant reduction in LPG in all of the eight muscles or groups of muscles tested $\left(4.84 \leq t_{(5)} \leq 19.6\right.$, $P<0.005)$. The reduction in larval burden was due to muscle growth and larval degeneration (Fig. 2). The proportion of these two factors reducing the larval burden varied according to the muscle or group of muscles and the time-point p.i. Muscle growth was the main factor in the reduced larval burden in all of the muscles tested and, particularly, in the tongue, masseter, shoulder, neck and loin at 6, 12, 18 and 24 months p.i. Conversely, the degeneration process followed by larval death played a primary role in the reduced larval burden in the diaphragm, ham, loin and ribs between 6 and 12 months p.i. and in the masseter between 12 and 18 months p.i. (Fig. 2).

At six months p.i., no T. britovi larvae were detected in the tongue and masseter, whereas some larvae were detected in the other six muscles or groups of muscles in the four pigs tested using digestion. The compressorium and histological examinations of diaphragm samples from a T. britovi-infected pig showed degenerated cysts with dead larvae (Fig. 3) and emptied cysts and cysts with larva with evident fibrosis (Fig. 4). It should be noted that no inflammatory cells were present around the nursecell-larva complexes (Fig. 4). No degenerated/calcified larvae were detected in the diaphragms of T. pseudospiralis-infected pigs by compressorium or histology at six months p.i. (data not shown).

\section{Infectivity of larvae from pig muscles in mice}

Trichinella spiralis larvae collected from the diaphragm showed an average RCI of 67 in CD1 mice, without significant statistical differences at 2, 6, 12, 18 and 24 months p.i. (data not shown). Trichinella britovi and T. pseudospiralis larvae collected from the diaphragm at two 

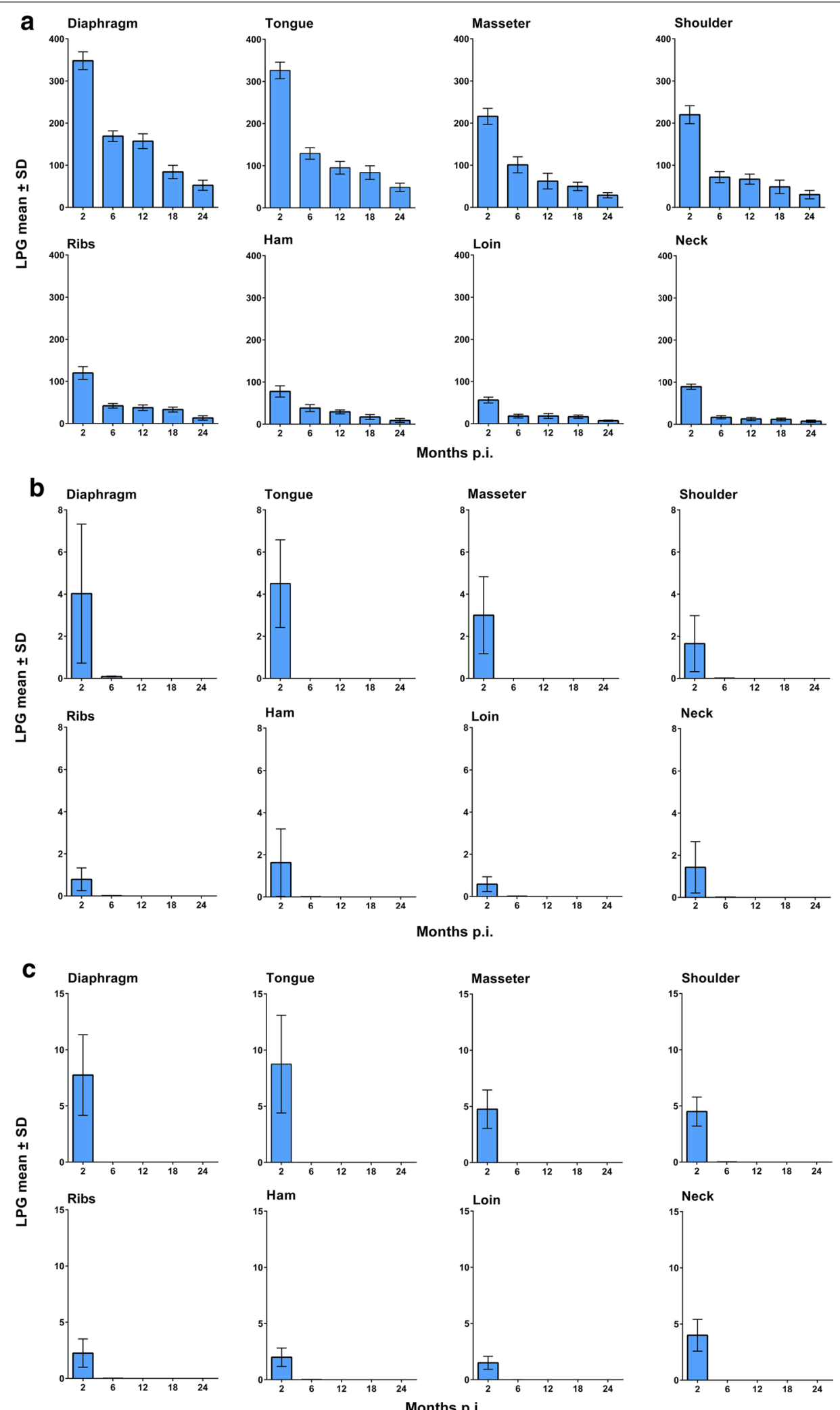

Fig. 1 Mean number ( \pm standard deviation, SD) of muscle larvae per g (LPG) in muscles or groups of muscles of Trichinella spiralis (a), Trichinella britovi (b) and Trichinella pseudospiralis (c) experimentally infected pigs at different months post-infection (p.i.) 
months p.i. showed an average RCI of 27 and 31 in CD1 mice, respectively. Trichinella britovi larvae detected in pig muscles at six months p.i. were very motile, suggesting infectivity, but there were too few of them to infect mice and thus calculate the RCI.

All 10 larvae collected from the diaphragms of T. spiralis-, T. britovi- and T. pseudospiralis-infected pigs at all time-points p.i. were correctly identified as belonging to the Trichinella species of the inoculum (data not shown).

\section{Immune response}

No statistically significant difference was observed between $\mathrm{E}_{\mathrm{I}}$ values detected by $\mathrm{ES}$ and crude antigens. Of 6 T. spiralis-infected pig sera tested 24 days post-infection (p.i.), only one was positive by ELISA. At 35 days p.i., all 19 T. spiralis-infected pig sera tested positive by ELISA. The $\mathrm{E}_{\mathrm{I}}$ values then reached a plateau (around $70 \%$ $\mathrm{E}_{\mathrm{I}}$ ) and remained stable until the end of the experimental period of just over two years, without any statistically significant trend over time (regression coefficient $(\beta)=$ $0.001, P=0.784$ ) (Fig. 5a).

Of 5 T. britovi-infected pig sera tested at 24 days p.i., there were no positive results by ELISA. At 35 days p.i., serum samples from 18 (90\%) T. britovi-infected pigs were positive by ELISA, and at 42 days p.i., the sera from the other two previously negative pigs had seroconverted. The $E_{I}$ values then increased up to an average of $70 \%$ (60 days p.i.), which persisted up to 300 days p.i. From that point onwards, the average $E_{I}$ value was around $60 \%$ until the end of the experiment, showing a slight statistically significant decrease over time $(\beta=-0.019, P=0.001)$ (Fig. 5b).

Of 5 T. pseudospiralis-infected pig sera tested at 24 days p.i., there were no positive results by ELISA. At 35 days p.i., serum samples from 17 (85\%) T. pseudospiralis-infected pigs were positive by ELISA, and at 42 days p.i., the sera from the other 3 previously negative pigs had seroconverted. The $E_{I}$ values then increased up to an average of $70 \%$ at 60 days p.i. Afterwards, the $E_{I}$ values showed a prominent statistically significant decrease $(\beta$ $=-0.093, P<0.001)$ up to 12 months p.i., when the mean of $E_{I}$ values fell below the cut-off (Fig. $5 \mathrm{c}$ ).

The comparison of the specific IgG levels among the three species revealed that at one month p.i., T. spiralis induced a higher level of anti-Trichinella IgG than $T$. britovi and T. pseudospiralis $\left(F_{(2,56)}=20.06, P<0.001\right)$, whereas at 6 months p.i. $\left(F_{(2,45)}=25.72, P<0.001\right)$ and 12 months p.i. $\left(F_{(2,33)}=29.36, P<0.001\right)$ there was a

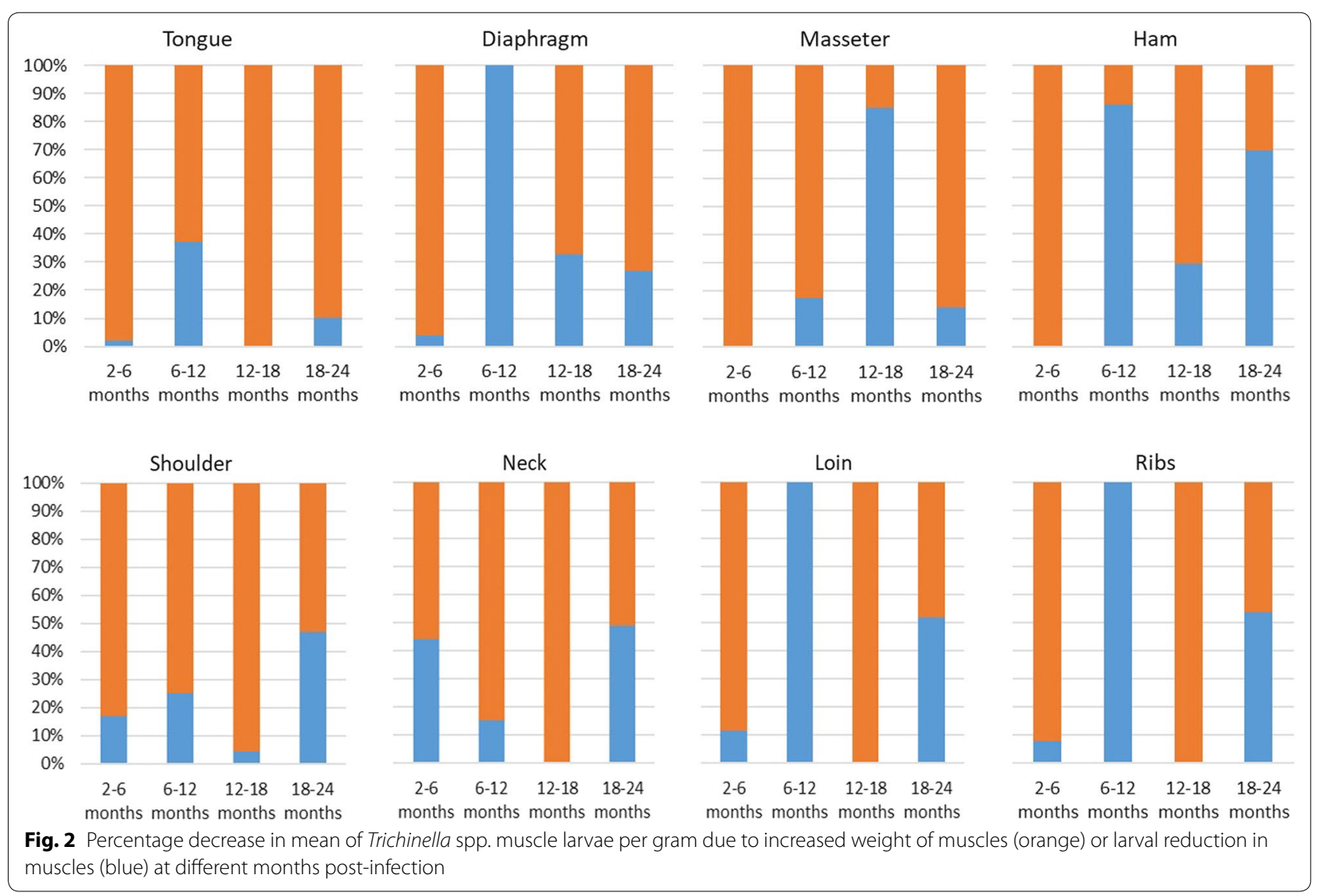



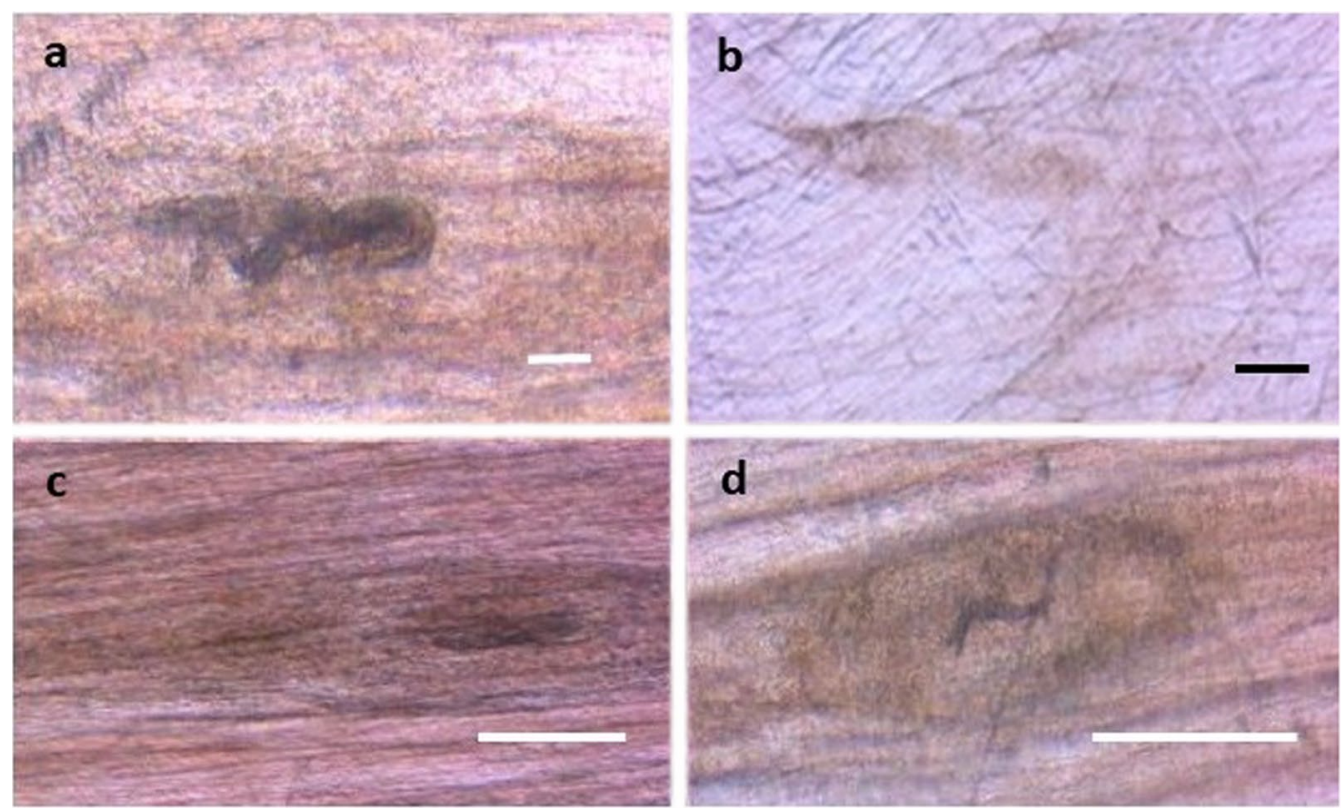

Fig. 3 Trichinella britovi nurse cell-larva complexes in a pig diaphragm by compressorium, six months post-infection. Scale-bars: a, $50 \mu \mathrm{m} ; \mathbf{b}, \mathbf{c}$, d $200 \mu \mathrm{m}$
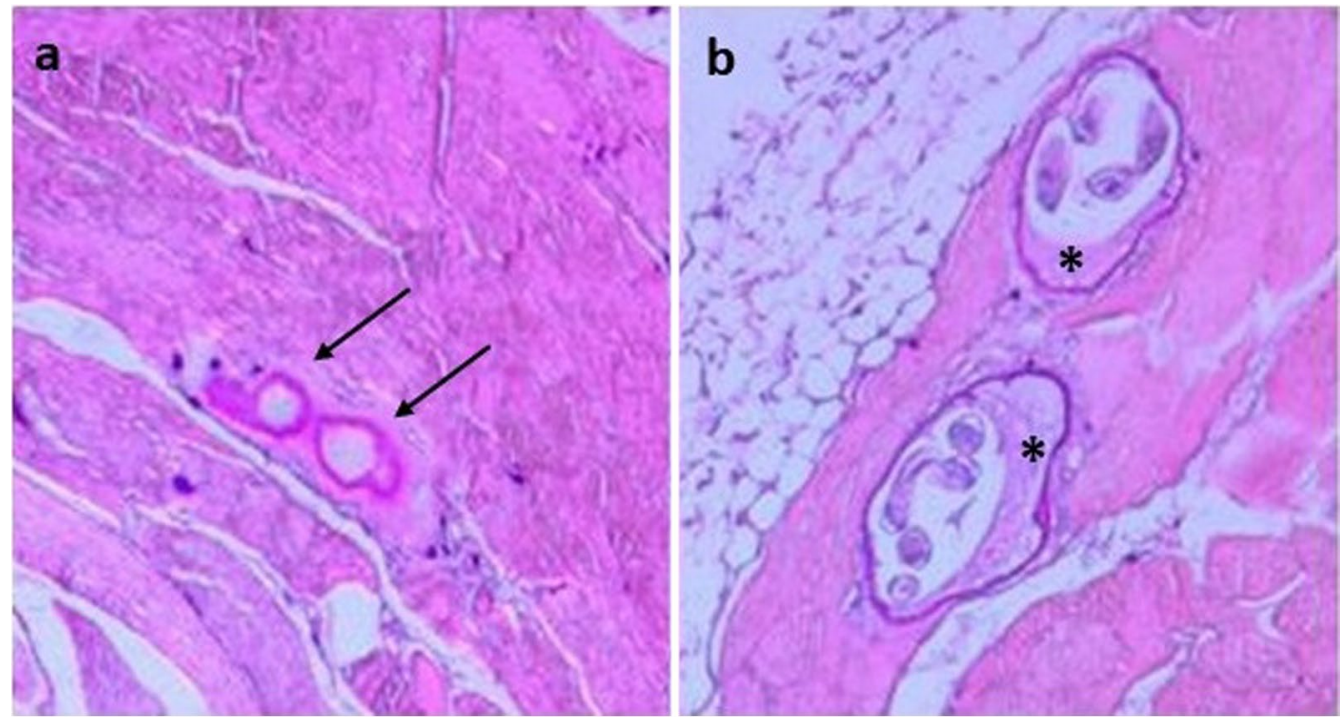

Fig. 4 Histology of Trichinella britovi nurse cell-larva complexes in a pig diaphragm, six months post-infection: empty cysts (arrows) at original magnification $50 \times(\mathbf{a})$; and cysts with fibrosis (asterisks) and larva inside at original magnification $100 \times(\mathbf{b})$

significant decrease in the specific IgG level in T. pseudospiralis-infected pigs (Fig. 5, Table 1). The correlation between the number of LPG and anti-Trichinella IgG by species, muscle/group of muscles and time-points is shown in Table 2. At two months p.i., there was a positive significant correlation between the number of LPG recovered from the diaphragm of pigs infected with $T$. pseudospiralis and the level of specific IgG $(r=0.99, P$ $<0.001$ ), whereas at the same time p.i., the correlation between both parameters was significantly negative in the loin muscle $(r=-0.99, P<0.001)$. A significant positive correlation was found for $T$. britovi-infected pigs only at 6 months p.i. $(r=0.95, P<0.001)$. For $T$. spiralis, no significant correlation of LPG was found, either by 


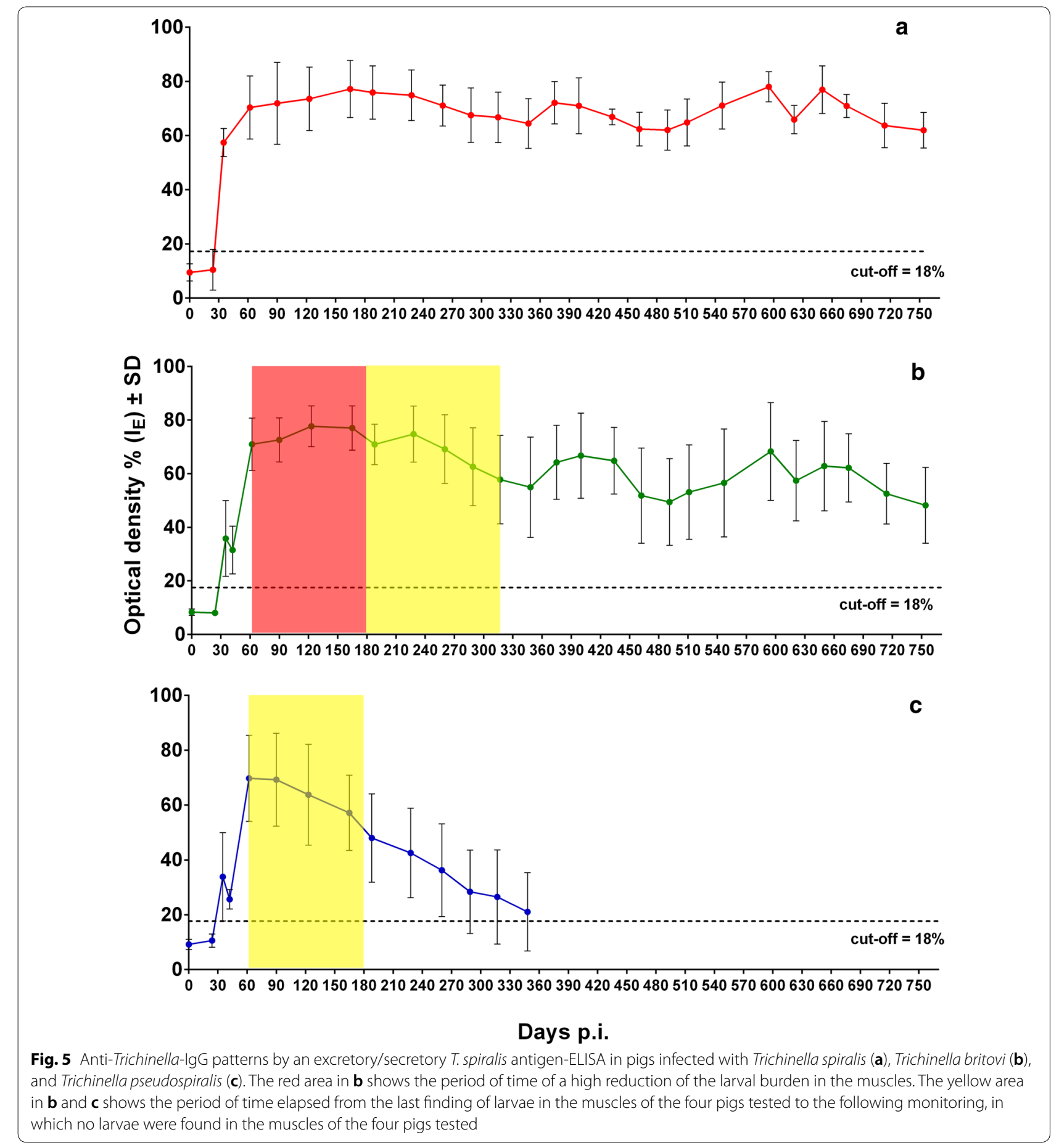

muscle or by time-point. The overall correlation between the number of LPG and anti-Trichinella IgG, without distinction by species, muscle/muscle group or time-point, was not significant $(r=0.27, P>0.05)$.

The western blot pattern of serum samples collected from T. spiralis- and T. britovi-infected pigs at 1, 2, 12 and 24 months p.i. showed the triple-band diagnostic pattern, irrespective of the presence ( $T$. spiralis) or absence (T. britovi) of larvae in the muscles at 12 and 24 months p.i. The pattern of serum samples collected from T. pseudospiralis-infected pigs at 2, 6 and 9 months p.i. showed the triple-band diagnostic pattern, irrespective 
of the presence (at 2 months p.i.) or absence (at 6 and 9 months p.i.) of larvae in the muscles (data not shown).

\section{Discussion}

The experimental infection of pigs showed three speciesspecific parasitological and immunological patterns. Trichinella spiralis larvae survived in the striated muscles of pigs for two years, with a seven-fold reduction in LPG in the diaphragm from two to 24 months p.i. (Fig. 1a). In all T. spiralis-infected pigs, seroconversion occurred within 35 days p.i., rapidly reached a plateau of about $70 \%$ $\mathrm{E}_{\mathrm{I}}$ at 62 days p.i., and then remained constant throughout the experimental period (Fig. 5a). Trichinella britovi larvae survived in the striated muscles of pigs for less than six months and very few motile larvae were detected in the diaphragm of one pig and in the diaphragm and five other muscle groups of another pig of the four animals tested at six months p.i. (Fig. 1b). The number of LPG in the diaphragm was 42 times lower than that detected at two months p.i. (Additional file 2: Table S1). Seroconversion occurred in all but two infected animals within 35 days p.i., reached an $\mathrm{E}_{\mathrm{I}}$ value of about $70 \%$ at two months p.i. and then decreased after eight months to an $\mathrm{E}_{\mathrm{I}}$ value of about $60 \%$. This value remained quite stable up to 23 months p.i., when the $\mathrm{E}_{\mathrm{I}}$ value declined to $50 \%$ at 24 months p.i. (Fig. 5b). Trichinella pseudospiralis larvae survived in the striated muscles of pigs for less than six months (Fig. 1c). Seroconversion occurred slowly, reached a peak of $70 \% \mathrm{E}_{\mathrm{I}}$ at about 60 days p.i. and then rapidly decreased to around the cut-off after ten months

Table 1 Comparison of anti-Trichinella lgG (ELISA index) mean among Trichinella spiralis, Trichinella britovi and Trichinella pseudospiralis at different times post-infection

\begin{tabular}{|c|c|c|c|c|c|}
\hline \multirow[t]{2}{*}{ Time (months p.i.) } & \multicolumn{3}{|c|}{ Mean anti-Trichinella IgG (SD) } & \multirow[t]{2}{*}{$P$-value ${ }^{a}$} & \multirow{2}{*}{$\begin{array}{l}\text { Statistically significant pairwise } \\
\text { comparison (Bonferroni adjusted) }\end{array}$} \\
\hline & T. spiralis & T. britovi & T.pseudospiralis & & \\
\hline 1 & $57.4(5.2)$ & $35.8(14.1)$ & $33.8(16.1)$ & $<0.001$ & T. spiralis vs T. britovi and T. pseudospiralis \\
\hline 2 & $70.3(11.7)$ & $71.0(9.8)$ & $69.7(15.7)$ & ns & \\
\hline 6 & $75.9(9.8)$ & $70.9(7.5)$ & $48.0(16.1)$ & $<0.001$ & T. pseudospiralis vs T. spiralis and T. britovi \\
\hline 12 & $64.5(9.2)$ & $54.9(18.7)$ & $21.0(14.3)$ & $<0.001$ & T. pseudospiralis vs T. spiralis and T. britovi \\
\hline 18 & $71.1(8.7)$ & $56.6(20.2)$ & na & ns & \\
\hline 24 & $61.9(6.6)$ & $48.2(14.1)$ & na & ns & \\
\hline
\end{tabular}

a ANOVA model

Abbreviations: na, not applicable; ns, not statistically significant $(P>0.05)$

Table 2 Correlation between larvae per gram and anti-Trichinella lgG (ELISA index) by species, muscle/group of muscles and time post-infection

\begin{tabular}{|c|c|c|c|c|c|c|c|c|}
\hline $\begin{array}{l}\text { Time (months } \\
\text { p.i.) }\end{array}$ & Tongue & Diaphragm & Masseter & Ham & Shoulder & Neck & Loin & Ribs \\
\hline \multicolumn{9}{|l|}{ T. spiralis } \\
\hline 2 & 0.592 & -0.172 & 0.649 & 0.138 & -0.240 & -0.800 & -0.304 & -0.56 \\
\hline 6 & 0.070 & -0.726 & 0.260 & -0.052 & -0.631 & -0.897 & -0.805 & -0.76 \\
\hline 12 & -0.484 & -0.132 & -0.584 & 0.231 & -0.245 & -0.636 & -0.027 & -0.232 \\
\hline 18 & 0.681 & -0.565 & -0.028 & 0.278 & 0.423 & 0.570 & -0.175 & -0.643 \\
\hline 24 & 0.709 & 0.604 & 0.076 & -0.515 & 0.384 & -0.223 & 0.432 & 0.298 \\
\hline \multicolumn{9}{|l|}{ T. britovi } \\
\hline 2 & 0.362 & 0.496 & 0.777 & 0.227 & 0.739 & 0.531 & 0.820 & 0.527 \\
\hline 6 & na & $0.954^{*}$ & na & 0.532 & 0.532 & 0.532 & 0.532 & 0.532 \\
\hline \multicolumn{9}{|l|}{ T.pseudospiralis } \\
\hline 2 & $0.991^{*}$ & -0.671 & -0.274 & -0.126 & 0.944 & 0.388 & $-0.990^{*}$ & -0.783 \\
\hline \multicolumn{9}{|l|}{ All species } \\
\hline 2 & 0.510 & 0.489 & 0.510 & 0.493 & 0.490 & 0.490 & 0.479 & 0.467 \\
\hline
\end{tabular}

* Statistically significant $(P<0.05)$

Abbreviation: na, not applicable 
(Fig. 5c). These three different biological and immunological patterns are in agreement with those found in previous investigations, which explored the parasitological and immunological patterns over a shorter period of time [6-8] and provide an explanation of the epidemiology of these three parasites.

The western blot triple-band diagnostic pattern of sera from T. spiralis-, T. britovi- and T. pseudospiralis-infected pigs did not change from two to 24 months p.i. (12 months p.i. for T. pseudospiralis). It follows that this pattern does not reveal the presence or absence of infecting larvae in the pig muscles, which would have been very useful for sero-epidemiological investigations.

According to an unpublished study, T. spiralis larvae survived and retained their infectivity in sow muscles for three years, but no data were recorded on detectable anti-Trichinella IgG in sera from these sows (K. D. Murrell, personal communication). In another study, T. spiralis larvae and anti-Trichinella IgG were detected in a pig infected with 5000 larvae 130 weeks earlier [36].

The detection of anti-Trichinella IgG in T. britoviinfected pigs at 24 months p.i. (Fig. $5 \mathrm{~b}$ ) in which viable larvae had been detected only 18 months earlier, can be explained by the immunogenicity of this parasite species and the persistence of the humoral immune responses due to the continuous release of Trichinella antigens from the encysted larvae before to become degenerated/ calcified. This hypothesis is supported by studies showing that humoral immune responses against $T$. britovi in humans can still be detected 15 years after infection [37, 38]. In T. pseudospiralis-infected pigs, the shorter period of survival of larvae in the muscles compared to T. brit$o v i$, the lack of a collagen capsule around the larva and the lower immunogenicity of the parasite in comparison with T. spiralis and T. britovi $[39,40]$ could explain the more rapid decrease in antibodies (Fig. 5c), given that no live larvae or degenerated/calcified larvae were detected at six months p.i.

The role of the swine race and Trichinella spp. strains in infection patterns has been investigated by several authors. At a high infection dose (20,000 larvae), $T$. britovi (ISS100) and T. pseudospiralis (ISS013) showed higher infectivity in Iberian pigs than German Yorkshire SPF pigs. However, no differences were observed at lower infecting doses (200 and 1000 larvae) [8]. Trichinella pseudospiralis strains from Europe (ISS013), North America (ISS470) and Australia (ISS141) showed different infection patterns in pigs (York $\times$ Duroc) and wild boar (S. scrofa). The infection patterns for $T$. spiralis (ISS004) and T. britovi (ISS100) were similar in both pigs (York $\times$ Duroc) and wild boar [6, 7]. All of these three studies concluded that $T$. spiralis is highly infective and T. britovi and T. pseudospiralis are moderately infective in swine. The results of this study are in agreement with these previous studies and highlight the T. spiralis-swine relationship, which dates back to the Pliocene epoch [41, 42].

According to the International Trichinella Reference Centre (EP, unpublished data), T. spiralis has been detected in 1153 (80.9\%) domestic pigs and 1468 (55.7\%) wild boar, T. britovi in 270 (18.9\%) domestic pigs and 1119 (42.4\%) wild boar, and T. pseudospiralis in two $(0.1 \%)$ domestic pigs and $49(1.8 \%)$ wild boar. These data confirm the results of epidemiological investigations carried out in Europe, where these three Trichinella species coexist $[15-18,43-51]$. The longer survival of $T$. spiralis in domestic pigs compared to the other two species highlights the exceptional dissemination potential conferred on $T$. spiralis by its association with domesticated swine and the maintenance of the domestic cycle. In Europe, backyard pigs are slaughtered in the wintertime and pork scraps from slaughter and uncooked pork scraps from the kitchen are inappropriately used to feed other pigs present in the backyard, which will be slaughtered in subsequent years. Conversely, the occurrence of T. britovi and, to a lesser extent, of T. pseudospiralis in domestic pigs can be explained by the practice used by hunters of feeding domestic pigs with leftovers from hunted wild boar or other wild animals in the hunting season, which precedes the slaughter of pigs by a few weeks and thus leaves just enough time for T. britovi and, to a lesser degree, $T$. pseudospiralis to develop in pig muscles. In central and southern European countries, where the prevalent species among wildlife is T. britovi, epidemiological investigations carried out following human outbreaks caused by the consumption of pork and/or pork-derived products from backyard or free-range pigs have in all cases shown a relationship with hunting activities [13, 52-56].

Epidemiological investigations on feral pigs in the USA carried out using serology and artificial digestion followed by larval species identification have shown a serological and parasitological prevalence of $2.9 \%$ and $1.81 \%$, respectively, and all larvae were identified as $T$. spiralis [28]. In a similar study carried out on wild boar in Italy, the serological and parasitological prevalence was $2.2 \%$ and $0.007 \%$, respectively, and all larvae were identified as T. britovi [27]. These epidemiological data are congruent with the results of this study. In fact, in the USA, where $T$. spiralis circulates among feral pigs, the serological prevalence was only 1.6 times higher than the parasitological prevalence. By contrast, in Italy, where T. britovi circulates among wild boar, the serological prevalence was 314 times higher than the parasitological prevalence due to the short survival period of T. britovi larvae in the muscles and the more lengthy persistence of anti-T. britovi IgG. 


\section{Conclusions}

The results presented here contribute to our understanding of the controversial data collected by parasitological and serological tools in the course of epidemiological investigations. The correlation between the presence of larvae in muscles and of anti-Trichinella IgG in serum samples for a time frame of at least two years, can be used for epidemiological purposes only in the regions where T. spiralis is the predominant species in domestic and/or wild swine. In these regions, serum epidemiological investigations will not only provide indications on host-parasite contacts but, with a certain approximation, also information on the number of infected animals.

\section{Supplementary information}

Supplementary information accompanies this paper at https://doi. org/10.1186/s13071-020-04394-7.

Additional file 1: Figure S1. Scatter plot of the ELISA index (EI) for anti-Trichinella spp. IgG in Trichinella free pigs from different European countries. ELISA was preformed using excretory/secretory antigens.

Additional file 2: Table S1. Mean number, standard deviation (SD) and 95\% confidence interval (CI) of larvae per g (LPG) of Trichinella spiralis, Trichinella britovi and Trichinella pseudospiralis in experimentally infected pigs at different times post infection.

\section{Abbreviations}

ANOVA: Analysis of variance; $\mathrm{Cl}$ : Confidence intervals; CWE: Crude worm extract; E/S: Excretory/secretory; E: ELISA index; ELISA: Enzyme-linked immunosorbent assay; IgG: Immunoglobulin G; LPG: Larvae per gram; OD: Optical density; p.i.: Post-infection; PCR: Polymerase chain reaction; $r$ : Regression coefficient; RT: Room temperature; SD: Standard deviation; TBST: Tween-Tris Buffered Saline; Wb: Western blot.

\section{Acknowledgements}

This study was supported in part by the European Commission, contract SANCO/2006/FOOD SAFETY/032

\section{Authors' contributions}

All authors have contributed significantly to this study. EP conceived, coordinated the study, and drafted the manuscript. GMe, EL, GDC and VF managed the experimental animals and their slaughtering. MF performed the statistical analysis. MA and AL prepared serum samples and carried out the immunoassays. SC performed histology and artificial digestion of muscle samples. MR and GR performed the carcass and muscle dissections and artificial digestions. MI performed artificial digestions and larva identification by PCR. GMa and DT performed artificial digestions of muscle samples. MAGM participated in the study design, interpreted the results and revised the manuscript. All authors read and approved the final manuscript.

\section{Funding}

Funding was provided by the European Commission and Istituto Superiore di Sanità.

\section{Availability of data and materials}

All data generated or analysed during this study are included in the article and its additional files.

Ethics approval and consent to participate

The study design was approved by the Animal Ethics Committee of the Ministry of Health (approval No 11/2016-UT).

\section{Consent for publication}

Not applicable.

\section{Competing interests}

The authors declare that they have no competing interests.

\section{Author details}

${ }^{1}$ Department of Infectious Diseases, Istituto Superiore di Sanità, viale Regina Elena 299, 00161 Rome, Italy. ${ }^{2}$ Istituto Zooprofilattico Sperimentale of Lombardy and Emilia Romagna, via Pietro Fiorini 5, 40127 Bologna, Italy. 3 Department of Public Health, Azienda Unità Sanitaria Locale of Modena, Strada Martiniana 21, 4112 Baggiovara, Modena, Italy. ${ }^{4}$ Consiglio per la ricerca in agricoltura e l'analisi dell'economia agraria, Centro di Ricerca Zootecnica e Acquacoltura, Sede di Modena, via Beccastecca 345, 41018 S. Cesario sul Panaro (MO), Italy.

Received: 24 July 2020 Accepted: 7 October 2020

Published online: 16 October 2020

\section{References}

1. Leidy J. Remarks on trichina. Proc Acad Anat Sci. 1846;3:107-8.

2. Zimmermann WJ. Trichinosis in the United States. In: Gould SE, editor. Trichinosis in man and animals. Springfield: C.C. Thomas; 1970. p. $378-400$

3. Murrell KD, Pozio E. Worldwide occurrence and impact of human trichinellosis, 1986-2009. Emerg Infect Dis. 2011;17:2194-202.

4. Mukaratirwa S, Foggin CM. Infectivity of Trichinella sp. isolated from Crocodylus niloticus to the indigenous Zimbabwean pig (Mukota). Int J Parasitol. 1999;29:1129-31.

5. Pozio E, Owen IL, La Rosa G, Sacchi L, Rossi P, Corona S. Trichinella papuae n. sp. (Nematoda), a new non-encapsulated species from domestic and sylvatic swine of Papua New Guinea. Int J Parasitol. 1999:29:1825-39.

6. Kapel CM, Gamble HR. Infectivity, persistence, and antibody response to domestic and sylvatic Trichinella spp. in experimentally infected pigs. Int Parasitol. 2000;30:215-21.

7. Kapel CM. Sylvatic and domestic Trichinella spp. in wild boars; infectivity, muscle larvae distribution, and antibody response. J Parasitol. 2001;87:309-14.

8. Nöckler K, Serrano FJ, Boireau P, Kapel CM, Pozio E. Experimental studies in pigs on Trichinella detection in different diagnostic matrices. Vet Parasitol. 2005;132:85-90.

9. Pozio E, Zarlenga DS. New pieces of the Trichinella puzzle. Int J Parasitol. 2013:43:983-97.

10. Sharma R, Thompson PC, Hoberg EP, Scandrett WB, Konecsni K, Harms $\mathrm{NJ}$, et al. Hiding in plain sight: discovery and phylogeography of a cryptic species of Trichinella (Nematoda: Trichinellidae) in wolverine (Gulo gulo). Int J Parasitol. 2020:50:277-87.

11. Beck JW. Trichinosis in domesticated and experimental animals. In: Gould SE, editor. Trichinosis in man and animals. Springfield: C. C. Thomas; 1970. p. $61-80$.

12. Campbell WC. Epidemiology I: modes of transmission. In: Campbell WC, editor. Trichinella and trichinosis. New York and London: Plenum Press; 1983. p. 425-44.

13. Pozio E, Cossu P, Marucci G, Amati M, Ludovisi A, Gómez-Morales MA, et al. The birth of a Trichinella britovi focus on the Mediterranean island of Sardinia (Italy). Vet Parasitol. 2009;159:361-3.

14. Cui J, Jiang P, Liu LN, Wang ZQ. Survey of Trichinella infections in domestic pigs from northern and eastern Henan China. Vet Parasitol. 2013;194:133-5.

15. EFS Agency. The European Union summary report on trends and sources of zoonoses, zoonotic agents and food-borne outbreaks in 2015. EFSA J. 2016:14:4634

16. EFS Agency. The European Union summary report on trends and sources of zoonoses, zoonotic agents and food-borne outbreaks in 2016. EFSA J. 2017;15:5077.

17. EFS Agency. The European Union summary report on trends and sources of zoonoses, zoonotic agents and food-borne outbreaks in 2017. EFSA J. 2018;16:5500.

18. EFS Agency. The European Union One Health 2018 Zoonoses Report. EFSA J. 2019;17:5926.

19. Berends BR, Smeets JF, Harbers AH, van Knapen F, Snijders JM. Investigations with enzyme-linked immunosorbent assays for Trichinella spiralis 
and Toxoplasma gondii in the Dutch 'Integrated Quality Control for finishing pigs' research project. Vet Q. 1991;13:190-8.

20. Venturiello SM, Ben GJ, Costantino SN, Malmassari SL, Nuñez GG, Veneroni RL, et al. Diagnosis of porcine trichinellosis: parasitological and immunoserological tests in pigs from endemic areas of Argentina. Vet Parasitol. 1998;74:215-28.

21. Joshi DD, Moller LN, Maharjan M, Kapel CM. Serological evidence of trichinellosis in local pigs of Nepal. Vet Parasitol. 2005;132:155-7.

22. Van der Giessen J, Fonvile M, Bouwknegt M, Langelaar M, Vollema A. Seroprevalence of Trichinella spiralis and Toxoplasma gondii in pigs from different housing systems in The Netherlands. Vet Parasitol. 2007;148:371-4.

23. Zivojinovic M, Dimitrijevic G, Lazic M, Petrovic M, Sofronic-Milosavljevic L. Trichinella prevalence in swine in an endemic district in Serbia: epidemiology and control. Vet Parasitol. 2009;159:358-60.

24. Richomme C, Lacour SA, Ducrot C, Gilot-Fromont E, Casabianca F, Maestrini $\mathrm{O}$, et al. Epidemiological survey of trichinellosis in wild boar (Sus scrofa) and fox (Vulpes vulpes) in a French insular region Corsica. Vet Parasitol. 2010;172:150-4.

25. Jokelainen $P$, Näreaho A, Hälli O, Heinonen M, Sukura A. Farmed wild boars exposed to Toxoplasma gondii and Trichinella spp. Vet Parasitol. 2012;187:323-7.

26. Cuttell L, Gómez-Morales MA, Cookson B, Adams PJ, Reid SA, Vanderlinde $P B$, et al. Evaluation of ELISA coupled with western blot as a surveillance tool for Trichinella infection in wild boar (Sus scrofa). Vet Parasitol. 2014;199:179-90.

27. Gómez-Morales MA, Ludovisi A, Amati M, Bandino E, Capelli G, Corrias F, et al. Indirect versus direct detection methods of Trichinella spp. infection in wild boar (Sus scrofa). Parasit Vectors. 2014;7:171.

28. Hill DE, Dubey JP, Baroch JA, Swafford SR, Fournet VF, Hawkins-Cooper $D$, et al. Surveillance of feral swine for Trichinella spp and Toxoplasma gondii in the USA and host-related factors associated with infection. Vet Parasitol. 2014;205:653-65.

29. Lee HJ, Chung OS, Kim JL, Lee SH, Yoo YB, Seo M. Seroprevalence of Trichinella sp. in Wild Boars (Sus scrofa) from Yanggu-gun, Gangwon-do Korea. Korean J Parasitol. 2015;53:233-6.

30. Kärssin A, Velström K, Gómez-Morales MA, Saar T, Jokelainen P, Lassen B. Cross-sectional study of anti-Trichinella antibody prevalence in domestic pigs and hunted wild boars in Estonia. Vector Borne Zoonotic Dis. 2016;16:604-10.

31. European Commission. Commission implementing regulation (EU) 2015/1375 of 10 August 2015 laying down specific rules on official controls for Trichinella in meat. Off J Eur Union. 2015:L212:7-34.

32. Pozio E, La Rosa G. Trichinella. In: Liu D, editor. Molecular detection of foodborne pathogens. Boca Raton: CRC Press; 2010. p. 851-63.

33. Gómez-Morales MA, Ludovisi A, Amati M, Blaga R, Zivojinovic M, Ribicich $\mathrm{M}$, et al. A distinctive western blot pattern to recognize Trichinella infections in humans and pigs. Int J Parasitol. 2012:42:1017-23.

34. Gómez-Morales MA, Ludovisi A, Pezzotti P, Amati M, Cherchi S, Lalle M, et al. International ring trial to detect anti-Trichinella lgG by ELISA on pig sera. Vet Parasitol. 2009;166:241-8.

35. Gómez-Morales MA, Ludovisi A, Amati M, Cherchi S, Tonanzi D, Pozio E. Differentiation of Trichinella species (Trichinella spiralis/Trichinella britovi versus Trichinella pseudospiralis) using western blot. Parasit Vectors. 2018;11:631.

36. Nöckler K, Voigt WP, Protz D, Miko A, Ziedler K. Intravitale Diagnostik der Trichinellose beim Schwein mit dem indirekten ELISA. Berl Münch Tierärztl Wschr. 1995;108:167-74.

37. Piergili-Fioretti D, Castagna B, Frongillo RF, Bruschi F. Re-evaluation of patients involved in a trichinellosis outbreak caused by Trichinella britovi 15 years after infection. Vet Parasitol. 2005;132:119-23.

38. Pinelli E, Mommers M, Kortbeek LM, Castagna B, Piergili-Fioretti D, Bruschi F. Specific lgG4 response directed against the $45-\mathrm{kDa}$ glycoprotein in trichinellosis: a re-evaluation of patients 15 years after infection. Eur J Clin Microbiol Infect Dis. 2007;26:641-5.

39. Wakelin D, Goyal PK, Dehlawi MS, Hermanek J. Immune responses to Trichinella spiralis and T. pseudospiralis in mice. Immunology. 1994;81:475-9.

40. Bruschi F, Pozio E, Watanabe N, Gómez-Morales MA, Ito M, Huang Y, et al. Anaphylactic response to parasite antigens: $\lg E$ and $\lg G 1$ independently induces death in Trichinella-infected mice. Int Arch Allergy Immunol. 1999:119:291-6.
41. Zarlenga DS, Rosenthal BM, La Rosa G, Pozio E, Hoberg EP. Post-Miocene expansion, colonization, and host switching drove speciation among extant nematodes of the archaic genus Trichinella. Proc Natl Acad Sci USA. 2006;103:7354-9.

42. Korhonen PK, Pozio E, La Rosa G, Chang BC, Koehler AV, Hoberg EP, et al. Phylogenomic and biogeographic reconstruction of the Trichinella complex. Nat Commun. 2016;7:10513.

43. Blaga R, Gherman C, Cozma V, Zocevic A, Pozio E, Boireau P. Trichinella species circulating among wild and domestic animals in Romania. Vet Parasitol. 2009;159:218-21.

44. Oivanen $L$, Oksanen A. Synanthropic Trichinella infection in Finland. Vet Parasitol. 2009;159:281-4.

45. Zivojinovic M, Sofronic-Milosavljevic L, Cvetkovic J, Pozio E, Interisano $\mathrm{M}$, Plavsic $\mathrm{B}$, et al. Trichinella infections in different host species of an endemic district of Serbia. Vet Parasitol. 2013;194:136-8.

46. Pozio E. Searching for Trichinella: not all pigs are created equal. Trends Parasitol. 2014;30:4-11.

47. Tolnai Z, Széll Z, Marucci G, Pozio E, Sréter T. Environmental determinants of the spatial distribution of Trichinella britovi and Trichinella spiralis in Hungary. Vet Parasitol. 2014;204:426-9.

48. Nicorescu IM, Ionita M, Ciupescu L, Buzatu CV, Tanasuica R, Mitrea IL. New insights into the molecular epidemiology of Trichinella infection in domestic pigs, wild boars, and bears in Romania. Vet Parasitol. 2015;212:257-61.

49. Oksanen A, Interisano M, Isomursu M, Heikkinen P, Tonanzi D, Oivanen $\mathrm{L}$, et al. Trichinella spiralis prevalence among wild life of a boreal region rapidly reduced in the absence of spillover from the domestic cycle. Vet Parasitol. 2018;262:1-5.

50. Petrović J, Grgić Ž, Prodanov Radulović J, Ratajac R, Urošević M, Pustahija $\mathrm{T}$, et al. Epidemiology of human trichinellosis in Vojvodina province, Serbia, from 2005 to 2016. Acta Vet Hung. 2019;67:40-50.

51. Bilska-Zając E, Różycki M, Grądziel-Krukowska K, Bełcik A, Mizak I, Karamon J, et al. Diversity of Trichinella species in relation to the host species and geographical location. Vet Parasitol. 2020;279:109052.

52. Pozio E, La Rosa G, Gómez-Morales MA. Epidemiology of human and animal trichinellosis in Italy since its discovery in 1887. Parasite. 2001;8(Suppl. 2):106-8.

53. Cortés-Blanco M, García-Cabañas A, Guerra-Peguero F, Ramos-Aceitero JM, Herrera-Guibert D, Martínez-Navarro JF. Outbreak of trichinellosis in Cáceres, Spain, December 2001-February 2002. Euro Surveill. 2002; 7:136-8.

54. Gómez-Garcia V, Hernandez-Quero J, Rodriguez-Osorio M. Short report: Human infection with Trichinella britovi in Granada. Spain Am J Trop Med Hyg. 2003;68:463-4.

55. Dubinský P, Antolová D, Reiterová K. Human Trichinella infection outbreaks in Slovakia, 1980-2008. Acta Parasitol. 2016;61:205-11.

56. Vutova K, Velev V, Chipeva R, Yancheva N, Petkova S, Tomov T, et al. Clinical and epidemiological descriptions from trichinellosis outbreaks in Bulgaria. Exp Parasitol. 2020;212:107874.

\section{Publisher's Note}

Springer Nature remains neutral with regard to jurisdictional claims in published maps and institutional affiliations.

Ready to submit your research? Choose BMC and benefit from:

- fast, convenient online submission

- thorough peer review by experienced researchers in your field

- rapid publication on acceptance

- support for research data, including large and complex data types

- gold Open Access which fosters wider collaboration and increased citations

- maximum visibility for your research: over 100M website views per year

At BMC, research is always in progress.

Learn more biomedcentral.com/submissions 